\title{
Systemic inflammatory response predicts outcome in patients undergoing resection for ductal adenocarcinoma head of pancreas
}

\author{
NB Jamieson', P Glen', DC McMillan*,', CJ McKay', AK Foulis'2, R Carter' and CW Imrie' \\ 'University Department of Surgery, Royal Infirmany, Glasgow G3I 2ER, UK; '² Department of Pathology, Royal Infirmary, Glasgow G3I 2ER, UK
}

\begin{abstract}
The aim of the present study was to examine the relationship between the clinicopathological status, the pre- and postoperative systemic inflammatory response and survival in patients undergoing potentially curative resection for ductal adenocarcinoma of the head of the pancreas. Patients $(n=65)$ who underwent resection of ductal adenocarcinoma of the head of pancreas between 1993 and 200I, and had pre- and postoperative measurements of C-reactive protein, were included in the study. The majority of patients had stage III disease (International Union Against Cancer Criteria, IUCC), positive circumferential margin involvement $\left(R_{1}\right)$, tumour size greater than $25 \mathrm{~mm}$ with perineural and lymph node invasion and died within the follow-up period. On multivariate analysis, tumour size (hazard ratio (HR) 2.10,95\% confidence interval $(\mathrm{Cl}) 1.20-3.68, P=0.009)$, vascular invasion $(\mathrm{HR} 2.58$, 95\% Cl I.48$4.50, P<0.00 \mathrm{I})$ and postoperative C-reactive protein $(H R 2.00,95 \% \mathrm{Cl} I .14-3.52, P=0.0 \mathrm{I} 5)$ retained independent significance. Those patients with a postoperative C-reactive protein $\leqslant 10 \mathrm{mg} \mathrm{I} \mathrm{I}^{-1}$ had a median survival of 21.5 months compared with 8.4 months in those patients with a C-reactive protein $>10 \mathrm{mgl}^{-1}(P<0.00 \mathrm{I})$. The results of the present study indicate that, in patients who have undergone potentially curative resection for ductal adenocarcinoma of the head of pancreas, the presence of a systemic inflammatory response predicts poor outcome.

British Journal of Cancer (2005) 92, 2 I-23. doi: I0.1038/sj.bjc.6602305 www.bjcancer.com
\end{abstract}

Published online 14 December 2004

(C) 2005 Cancer Research UK

Keywords: pancreatic cancer; curative resection; tumour size; C-reactive protein; survival

The outlook for patients with ductal adenocarcinoma of the head of the pancreas remains poor, having the lowest 5-year survival rate of any cancer (Parker et al, 1996). Surgery remains the only proven approach for improving survival in these patients. However, surgery is complicated and is associated with appreciable morbidity and mortality. As a consequence, potentially curative surgery is carried out relatively infrequently and usually in a specialist centre.

The prognosis for patients who undergo potentially curative resection has been reported to be determined by various pathologic characteristics of the resected tumour specimen. Pathologic predictors of survival after surgery include vascular invasion (Griffanti-Bartoli et al, 1994), perineural invasion (Hermanek, 1998; Ozaki et al, 1999), histological tumour grade (Greer and Brennan, 1993), not achieving a clear margin (Yeo et al, 1995) and tumour size (Fortner et al, 1996). Taking all these factors into account, Fortner and co-workers (1996) reported that, in 52 patients undergoing potentially curative regional pancreatectomy, tumour size was the strongest predictor of survival independent of lymph node metastases.

It is increasingly recognised that it is not only the intrinsic properties of tumour cells which determine tumour spread but also the host inflammatory response (Balkwill and Mantovani,

\footnotetext{
*Correspondence: Dr DC McMillan;

E-mail: d.c.mcmillan@clinmed.gla.ac.uk

Received 6 August 2004; revised 26 October 2004; accepted 8 November 2004; published online 14 December 2004
}

2001; Coussens and Werb, 2002). Indeed, the systemic inflammatory response, as evidenced by elevated circulating concentrations of C-reactive protein, has been shown to be a disease-independent prognostic factor in a variety of operable tumours (Mahmoud and Rivera, 2002; McMillan et al, 2003; Ikeda et al, 2003). In particular, an elevated C-reactive protein, measured either prior to or following curative surgery, has been shown to predict recurrence and overall survival, independent of stage, in patients with colorectal cancer (McMillan et al, 2003).

An elevated C-reactive protein concentration has previously been shown to have independent prognostic value in patients with unresectable pancreatic ductal adenocarcinoma (Falconer et al, 1995; Ueno et al, 2000; Engelken et al, 2003). However, to our knowledge the prognostic value of C-reactive protein has not been previously examined in patients with operable disease.

The aim of the present study was to examine the relationship between clinicopathologic status, the systemic inflammatory response and survival in patients undergoing potentially curative resection for ductal adenocarcinoma of the head of the pancreas.

\section{PATIENTS AND METHODS}

\section{Patients}

Patients who on the basis of radiological and pathological staging underwent resection of ductal adenocarcinoma of the head of pancreas (between 1st January 1993 and 31st July 2001) had preand postoperative measurements of $\mathrm{C}$-reactive protein, and 
postoperative measurements of tumour size were included in the study. Measurement of C-reactive protein was carried out on the day prior to and approximately 1 month following surgery. All patients underwent either a classic Whipple's procedure or a pylorus preserving resection for removal of ductal adenocarcinoma of the head of pancreas. Patients with ampullary, periampullary and duodenal carcinoma were excluded from study as well as pancreatic neuroendocrine tumours. Patients presenting either with cholangitis or other clinical evidence of infection, especially where the bile culture was positive, were also excluded from study.

All patients were treated in the upper GI surgical unit at Glasgow Royal Infirmary and survived at least 30 days following surgery. No patient underwent chemotherapy. The study was approved by the local ethical committee.

\section{Methods}

Tumours were classified by type, along with pathological staging criteria (size, nodal status, perineural and vascular invasion, and tumour differentiation). Tumour stage was according to the International Union Against Cancer Criteria (IUCC). Tumour size was taken as the largest tumour diameter measured by the pathologist.

Routine laboratory measurements of albumin and bilirubin were carried out. C-reactive protein was measured by Fluorescence Polarisation Immunoassay using an Abbott TDX analyser and Abbott reagents (Abbott Laboratories, Abbott Park, IL, USA). The coefficient of variation for this method, over the range of measurement, was less than $5 \%$ as established by routine quality control procedures. The limit of detection of the assay is a Creactive protein concentration of less than $5 \mathrm{mgl}^{-1}$ with the upper limit of normal values being $\leqslant 10 \mathrm{mg} \mathrm{l}^{-1}$. Based on previous work (O'Gorman et al, 2000), a C-reactive protein concentration of greater than $10 \mathrm{mgl}^{-1}$ was considered to indicate the presence of a systemic inflammatory response.

\section{Statistics}

Comparisons between groups of patients were carried out using contingency table analysis $\left(X^{2}\right)$ as appropriate. Survival analysis was performed using the Cox's proportional-hazards model. Deaths up to the end of March 2004 were included in the analysis. Multivariate survival analysis was performed using a stepwise backward procedure to derive a final model of the variables that had a significant independent relationship with survival. To remove a variable from the model, the corresponding $P$-value had to be greater than 0.10. Analysis was performed using SPSS software (SPSS Inc., Chicago, IL, USA).

\section{RESULTS}

Baseline characteristics of the patients $(n=65)$ studied are shown in Table 1. The majority of patients were under 65 years with similar numbers of male and female patients. The majority of patients had stage III disease (IUCC), positive circumferential margin involvement $\left(\mathrm{R}_{1}\right)$, tumour size greater than $25 \mathrm{~mm}$ with perineural and lymph node invasion. The tumour was well differentiated in $12 \%$, moderate in $55 \%$ and poor in the $32 \%$.

In all, 33 patients (51\%) had evidence of a systemic inflammatory response preoperatively, that is, circulating Creactive protein concentration greater than $10 \mathrm{mgl}^{-1}$. During the follow-up period, 60 (92\%) patients died. The median survival time was 13.4 months.

On univariate analysis, sex $(P<0.05)$, tumour size $(P<0.05)$, vascular invasion $(P<0.001)$, preoperative $(P<0.001)$ and postoperative $(P<0.001) \quad$ C-reactive protein concentrations were significantly associated with survival (Table 1). On multivariate
Table I Characteristics of patients who underwent potentially curative resection for ductal adenocarcinoma of the head of the pancreas: univariate survival analysis

\begin{tabular}{|c|c|c|c|}
\hline & $\begin{array}{l}\text { Patients } \\
(n=65)\end{array}$ & HR $(95 \% \mathrm{CI})$ & $P$-value \\
\hline Age $(<65 />65$ years $)$ & $37 / 28$ & $0.66(0.39-1.12)$ & 0.127 \\
\hline $\operatorname{Sex}(f / m)$ & $33 / 32$ & $1.78(1.06-2.99)$ & 0.031 \\
\hline Stage (I/II/III) & $17 / 2 / 46$ & $1.13(0.83-1.53)$ & 0.449 \\
\hline Resection margin RO/RI & $19 / 46$ & $1.64(0.92-2.91)$ & 0.094 \\
\hline Tumour size $(\leqslant 25 />25 \mathrm{~mm})$ & $27 / 38$ & $1.99(1.14-3.45)$ & 0.015 \\
\hline Lymph node invasion $(-/+)$ & $20 / 45$ & $1.25(0.7 \mid-2.22)$ & 0.444 \\
\hline Perineural invasion $(-/+)$ & $6 / 59$ & $1.01(0.44-2.37)$ & 0.973 \\
\hline Vascular invasion $(-/+)$ & $39 / 26$ & $2.75(1.60-4.71)$ & $<0.001$ \\
\hline $\begin{array}{l}\text { Tumour differentiation (well/ } \\
\text { moderate/poor) }\end{array}$ & $8 / 36 / 21$ & $1.46(0.97-2.20)$ & 0.072 \\
\hline Albumin $\left(\geqslant 35 /<35 \mathrm{gl}^{-1}\right)$ & $40 / 25$ & $1.00(0.59-|.7|)$ & 0.987 \\
\hline Bilirubin $\left(\leqslant 22 />22 \mu \mathrm{moll}^{-1}\right)$ & $12 / 53$ & $1.12(0.56-2.23)$ & 0.750 \\
\hline $\begin{array}{l}\text { Biliary stent (no/yes) } \\
\text { Preoperative }\end{array}$ & $32 / 33$ & $1.06(0.63-1.76)$ & 0.836 \\
\hline $\begin{array}{l}\text { C-reactive protein }(\leqslant 10 / \\
\left.>10 \mathrm{mg}^{-1}\right) \\
\text { Postoperative }\end{array}$ & $32 / 33$ & $2.56(|.5|-4.36)$ & $<0.001$ \\
\hline $\begin{array}{l}\text { C-reactive protein }(\leqslant 10 / \\
\left.>10 \mathrm{mgl}^{-1}\right)\end{array}$ & $33 / 32$ & $2.50(1.46-4.29)$ & $<0.001$ \\
\hline
\end{tabular}

$\mathrm{Cl}=$ confidence interval; $\mathrm{HR}=$ hazard ratio

analysis of these significant variables, tumour size (hazard ratio (HR) $2.10,95 \%$ confidence interval (CI) 1.20-3.68, $P=0.009$ ), vascular invasion (HR 2.58, 95\% CI 1.48-4.50, $P<0.001)$ and postoperative C-reactive protein (HR 2.00, 95\% CI 1.14-3.52, $P=0.015)$ retained independent significance. The patient group with no evidence of a postoperative systemic inflammatory response (C-reactive protein $\leqslant 10 \mathrm{mgl}^{-1}$ ) had a median survival of 21.5 months compared with 8.4 months in the elevated systemic inflammatory response group $(P<0.001)$.

The relationship between the presence of an elevated preoperative C-reactive protein concentration and tumour characteristics are shown in Table 2. There was no significant difference in the stage, presence of positive resection margins, lymph node metastases or perineural invasion between the inflammatory and noninflammatory groups. There were a greater number of males $(P<0.05)$ and tumours were larger $(P<0.05)$, had more vascular invasion $(P<0.05)$ and had poorer differentiation $(P<0.05)$ in the elevated C-reactive protein group.

\section{DISCUSSION}

Surgical resection remains the only prospect for long-term survival in patients with ductal adenocarcinoma of the pancreas. Currently, in patients undergoing surgery, prognostic factors are all based on the pathological findings from the resected tumour. However, this means that the assessment of prognosis occurs following a major operation with significant morbidity and mortality. Therefore, it is of interest that in the present study an elevated circulating concentration of C-reactive protein $\left(>10 \mathrm{mgl}^{-1}\right)$, measured preoperatively, was associated with poor survival and was associated with pathological criteria indicative of poor outcome.

It has been previously shown that, in patients with primary operable colorectal cancer, approximately one-third of patients had an elevated circulating concentration of C-reactive protein preoperatively and that these patients had a significantly poorer outcome (McMillan et al, 2003). It was of interest that, in the present study, the proportion of patients with an elevated 
Table 2 The relationship between the presence of a preoperative systemic inflammatory response and tumour characteristics of ductal adenocarcinoma of the head of the pancreas

\begin{tabular}{|c|c|c|c|}
\hline & $\begin{array}{l}\text { C-reactive } \\
\text { protein } \\
\leqslant 10 \mathrm{mgI}^{-1} \\
(\mathrm{n}=32)\end{array}$ & $\begin{array}{c}\text { C-reactive } \\
\text { protein }>10 \mathrm{mg} \mathrm{I}^{-1} \\
\quad(n=33)\end{array}$ & $P$-value \\
\hline Age $\leqslant 65 />65$ years) & $15 / 17$ & $22 / 11$ & 0.107 \\
\hline $\operatorname{Sex}(f / m)$ & $21 / 11$ & $12 / 21$ & 0.018 \\
\hline Stage (I/I/I/III) & $9 / 2 / 21$ & $8 / 0 / 25$ & 0.302 \\
\hline Resection margin RO/RI & $|1 / 2|$ & $8 / 25$ & 0.369 \\
\hline $\begin{array}{l}\text { Tumour size }(\leqslant 25 / \\
>25 \mathrm{~mm})\end{array}$ & $18 / 14$ & $9 / 24$ & 0.018 \\
\hline $\begin{array}{l}\text { Lymph node invasion (-/ } \\
+ \text { ) }\end{array}$ & $12 / 20$ & $8 / 25$ & 0.247 \\
\hline Perineural invasion $(-/+)$ & $4 / 28$ & $2 / 31$ & 0.370 \\
\hline Vascular invasion $(-/+)$ & $24 / 8$ & $15 / 18$ & 0.015 \\
\hline $\begin{array}{l}\text { Tumour differentiation } \\
\text { (well/moderate/poor) }\end{array}$ & $6 / 21 / 5$ & $2 / 15 / 16$ & 0.013 \\
\hline Albumin $\left(\geqslant 35 /<35 \mathrm{gl}^{-1}\right)$ & $23 / 9$ & $17 / 16$ & 0.092 \\
\hline Bilirubin $(\leqslant 22 />22)$ & $26 / 6$ & $27 / 6$ & 0.953 \\
\hline $\begin{array}{l}\text { Biliary stent (no/yes) } \\
\text { Postoperative }\end{array}$ & $18 / 14$ & $14 / 19$ & 0.265 \\
\hline $\begin{array}{l}\text { C-reactive protein }(\leqslant 10 / \\
\left.>10 \mathrm{mg} \mathrm{I}^{-1}\right)\end{array}$ & $17 / 15$ & $10 / 23$ & 0.062 \\
\hline Survival (months) ${ }^{a}$ & $18.2(14.9-21.4)$ & $8.3(6.6-10.0)$ & $<0.001$ \\
\hline
\end{tabular}

a Median ( $95 \%$ confidence interval).

preoperative C-reactive protein concentration was approximately half and that these patients also had a poorer outcome. It may be that because $\mathrm{C}$-reactive protein concentration is independent of tumour stage, it might form the basis of a new prognostic score that reflects not only the tumour response but also that of the host.
Indeed, this approach has recently been used to improve the prediction of outcome in patients who underwent potentially curative resection for oesophageal and colorectal cancer (Ikeda et al, 2003; Canna et al, 2004).

In the present study, an elevated C-reactive protein concentration, measured either pre- or postoperatively, was associated with more than a halving of survival. When, in multivariate survival analysis, an elevated preoperative C-reactive protein was compared with the postoperative (1 month) value, an elevated postoperative C-reactive protein better predicted poor survival independent of pathological criteria. Although from the present results an elevated postoperative C-reactive concentration is a better predictor of survival than an elevated preoperative value, in a clinical context, the measurement of pre- and postoperative C-reactive protein concentrations are both likely to be of value. The preoperative measurement, since it may allow planning of adjuvant treatment, and the postoperative measurement, since it may be useful in the monitoring of patients who have undergone resection for ductal adenocarcinoma of the head of the pancreas.

This is a retrospective study and requires verification in larger prospective cohorts. However, if an elevated C-reactive protein concentration is shown to predict a poorer prognosis, it may be the case that patients with potentially resectable ductal adenocarcinoma of the head of the pancreas, yet a high inflammatory profile preoperatively, should not undergo surgery. Alternatively, modulation of the systemic inflammatory response may be a useful approach in these patients in the postoperative period.

In summary, the results of the present study indicate that, in patients who have undergone potentially curative resection for ductal adenocarcinoma of the head of pancreas, the presence of a systemic inflammatory response predicts poor outcome.

\section{ACKNOWLEDGEMENTS}

We gratefully acknowledge the assistance of Diane Stewart, Audit Coordinator, Department of Surgery, Royal Infirmary, Glasgow.

\section{REFERENCES}

Balkwill F, Mantovani A (2001) Inflammation and cancer: back to Virchow? Lancet 357(9255): 539-545

Canna K, McMillan DC, McKee RF, McNicol AM, Smith GW, Horgan PG, McArdle CS (2004) Evaluation of a cumulative prognostic score based on the systemic inflammatory response in patients undergoing potentially curative surgery for colorectal cancer. Br J Cancer 90: 1707- 1709

Coussens LM, Werb Z (2002) Inflammation and cancer. Nature 420(6917): $860-867$

Engelken FJ, Bettschart V, Rahman MQ, Parks RW, Garden OJ (2003) Prognostic factors in the palliation of pancreatic cancer. Eur J Surg Oncol 29: $368-373$

Falconer JS, Fearon KC, Ross JA, Elton R, Wigmore SJ, Garden OJ, Carter DC (1995) Acute-phase protein response and survival duration of patients with pancreatic cancer. Cancer 75: 2077-2082

Fortner JG, Klimstra DS, Senie RT, Maclean BJ (1996) Tumor size is the primary prognosticator for pancreatic cancer after regional pancreatectomy. Ann Surg 223: 147-153

Greer RJ, Brennan MF (1993) Resection of pancreatic adenocarcinoma: Prognostic indicators for survival. Am J Surg 195: 68-73

Griffanti-Bartoli F, Arnone GB, Ceppa P, Ravera G, Carrabetta S, Civalleri D (1994) Malignant tumors in the head of the pancreas and the periampullary region. Diagnostic and prognostic aspects. Anticancer Res 14(2B): $657-666$

Hermanek P (1998) Pathology and biology of pancreatic ductal adenocarcinoma. Langenbecks Arch Surg 383: 116-120
Ikeda M, Natsugoe S, Ueno S, Baba M, Aikou T (2003) Significant host- and tumor-related factors for predicting prognosis in patients with esophageal carcinoma. Ann Surg 238: 197-202

Mahmoud FA, Rivera NI (2002) The role of C-reactive protein as a prognostic indicator in advanced cancer. Curr Oncol Rep 4: 250-255

McMillan DC, Canna K, McArdle CS (2003) Systemic inflammatory response predicts survival following curative resection of colorectal cancer. Br J Surg 90: 215-219

Ozaki H, Hiraoka T, Mizumoto R, Matsuno S, Matsumoto Y, Nakayama T, Tsunoda T, Suzuki T, Monden M, Saitoh Y, Yamauchi H, Ogata Y (1999) The prognostic significance of lymph node metastasis and intrapancreatic perineural invasion in pancreatic cancer after curative resection. Surg Today 29: $16-22$

O'Gorman P, McMillan DC, McArdle CS (2000) Factors predicting survival of advanced gastrointestinal cancer patients with weight loss. Nutr Cancer 37: $36-40$

Parker SL, Tong T, Bolden S, Wingo PA (1996) Cancer statistics, 1996. CA Cancer J Clin 46: 5-27

Ueno H, Okada S, Okusaka T, Ikeda M (2000) Prognostic factors in patients with metastatic pancreatic adenocarcinoma receiving systemic chemotherapy. Oncology 59: 296-301

Yeo CJ, Cameron JL, Lillemoe KD, Sitzmann JV, Hruban RH, Goodman SN, Dooley WC, Coleman J, Pitt HA (1995) Pancreaticoduodenectomy for cancer of the head of the pancreas. 201 patients. Ann Surg 221: $721-731$ 